\title{
Experimental characterization of an electrospindle with gas bearings
}

\author{
G. Belforte, F. Colombo, T. Raparelli, A. Trivella \& V. Viktorov \\ Department of Mechanical and Aerospace Engineering, \\ Politecnico di Torino, Italy
}

\begin{abstract}
Fluid film bearings are a possible solution to be adopted in very high speed applications if the operating speeds overcome the maximum rotational speeds of rolling bearings. In particular, gas bearings offer important advantages thanks to the low viscosity of air and to the peculiarity of being non-contact systems. For these properties they are characterized by low friction, high accuracy and life almost unlimited.

In machine tools, gas bearings are adopted in applications that usually are limited to electrospindles of small dimensions (like e.g. high speed grinding, milling, PCB drilling and coatings).

For this reason in this paper the applicability of gas bearings for a larger electrospindle for machining process is investigated. The spindle, of $50 \mathrm{~mm}$ diameter, is accelerated by an asynchronous motor of nominal speed $75 \mathrm{krpm}$ and power $2.5 \mathrm{~kW}$.

A test bench was designed and realized to perform static and dynamic characteristics of the spindle and to allow the measurement of the cutting loads during machining. The experimental characterization of the electrospindle is shown. In particular, the static stiffness of gas bearings and the air consumption were measured at different supply pressures. The dynamic tests consisted of measuring the rotor runout without external loads and also during the machining process. In this condition, the dynamic forces on the tool were detected using HSS and HSC cutters of diameters from 1 to $6 \mathrm{~mm}$. Some preliminary results are reported.
\end{abstract}

Keywords: gas lubrication, high speed electrospindle, gas bearings. 


\section{Introduction}

Gas bearings use a thin film of air to separate two bodies and support a load. They have a relatively recent history: significant progress was made in developing air bearing technology from 1940s thanks to defence industries. Recently the attention on gas bearings has greatly increased due to the importance of precision technology. They are used for applications in which high precision and high speeds are necessary: in the first case air pads represent the fundamental component of a measuring machine; in the second case they are a valid solution to support rotors up to speeds not tolerated by rolling bearings. An example of application of such bearings are the smart electrospindles for very high speed [1-3], in which the spindle must be supported in stable conditions up to 200-250 krpm [4]. Other application sectors are micro-turbomachines [5] and movable electric appliances [6].

As regards electrospindles for milling and grinding, the torques required to the motor decrease with the speed. In Figure 1 are collected the characteristics of commercial electrospindles for various applications in terms of torque vs. speed. Also cutting forces decrease with the speed and the power required for machining at very high speeds is much lower with respect to the power available on the motor.

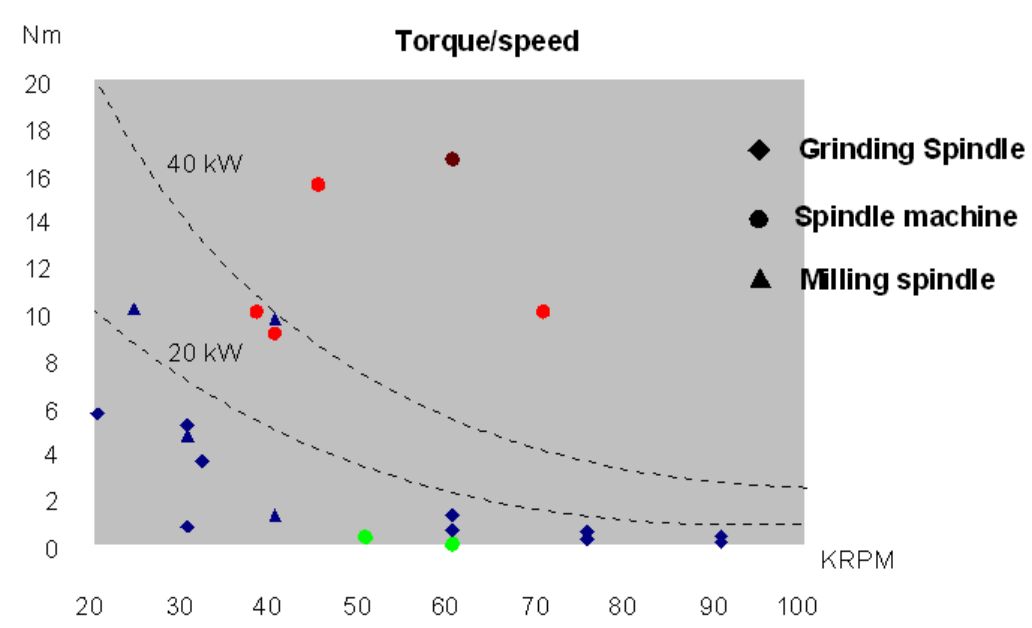

Figure 1: Characteristics of commercially available high speed electrospindles.

In order to reach higher speeds commercial electrospindles use gas bearings because of their low friction and their contact free characteristics.

In this paper a prototype of electrospindle supported by means of gas bearings is presented. Such a prototype differs from similar electrospindles only for the use of gas bearings instead of rolling bearings, but it has comparable dimensions. It was designed, realized and tested at Politecnico di Torino to demonstrate the 
suitability of this technology in work machines. A numerical model [7, 8] was used to calculate the pressure distribution in air bearings and obtain the stiffness and the load capacity of the spindle. In paper [9] the first tests without machining were shown. The spindle rotated in stable conditions but its dynamic runout was high, so a better grade of balancing was required. The spindle described in this paper was rebalanced and tested also during machining.

\section{Prototype description}

The prototype (see figure 2) is composed of a spindle (1) of diameter $50 \mathrm{~mm}$ and length $480 \mathrm{~mm}$, supported by two radial bushings (2a, 2b) and a double thrust bearing (3). Proper supply channels for air are provided in carter (4) to feed the externally pressurized gas bearings. Other channels (5) are provided to realize a closed cooling circuit for refrigerant. Each radial bearing is endowed with 16 calibrated holes of diameter $0.4 \mathrm{~mm}$. This diameter was modified respect to the prototype described in paper [9] in order to obtain a higher stiffness on the bearings. On each disk of the thrust bearing are present 8 calibrated holes of 0.2 $\mathrm{mm}$, equispaced on a circumference of diameter $65 \mathrm{~mm}$. The spindle is accelerated by the three phase asynchronous motor (6), with nominal speed 75 $\mathrm{krpm}$ and nominal power $2.5 \mathrm{~kW}$. On the opposite side of the motor a clamping tool is screwed to the nose (7) of the spindle. An optical tachometer (8) facing the motor is used to measure the rotational speed. For each bearing a couple of capacitive displacement transducers $(9,10)$ are mounted on planes perpendicular to the spindle axis. The transducers have 0.1 micron resolution, 500 micron full scale reading and $6 \mathrm{kHz}$ passband. Their signals allow us to acquire the orbit of the rotor inside the bushings by means a $500 \mathrm{kS} / \mathrm{s}$ 12-bit National Instruments card.

Figure 3 shows a view of the statoric parts of the spindle and the motor in which are visible the axial channels for the refrigerant, that is pumped in a close cooling circuit.

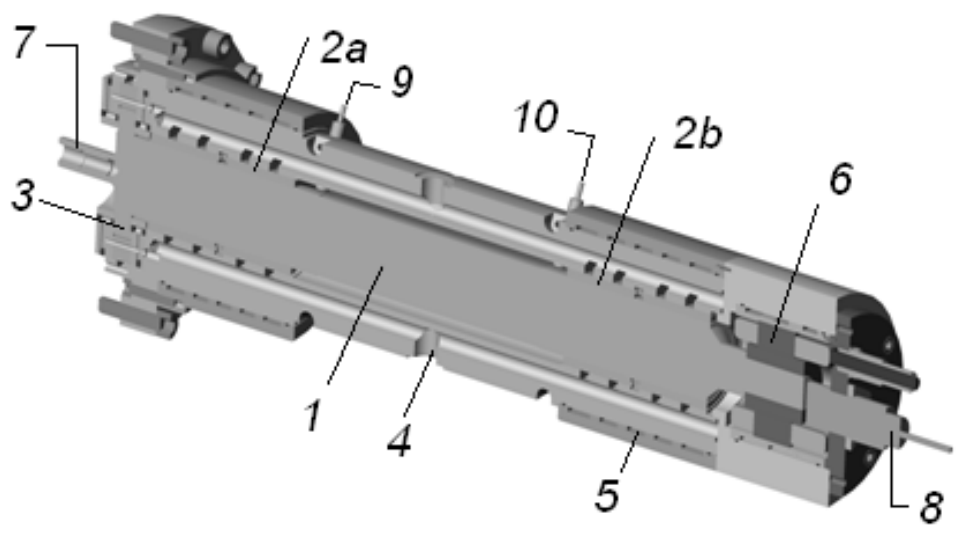

Figure 2: Section of the electrospindle. 


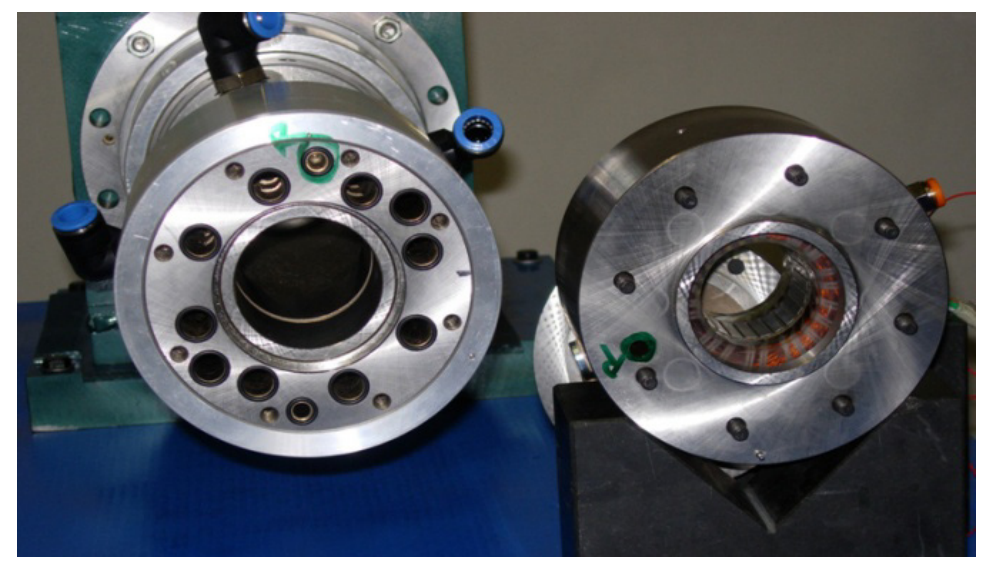

Figure 3: $\quad$ Statoric parts of the electric spindle.

Two high efficiency air filters (97\% and 99\% efficiency with particles of diameter $0.1 \mu \mathrm{m}$ ) avoid clogging of the supply orifices.

A test bench to measure static and dynamic characteristics of the spindle was developed. The spindle was mounted vertically on a rigid basement with the tool mounted on the bottom side. Static radial and axial bearing stiffness are obtained loading the extremity of the spindle with the system shown in figure 4 .

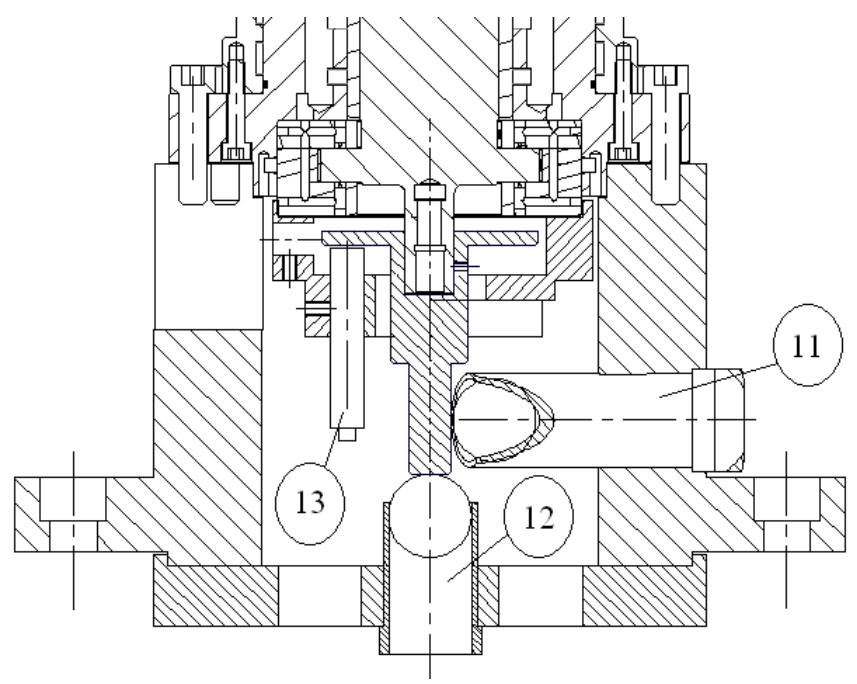

Figure 4: $\quad$ Load devices for static measurements.

The system is composed of hollow cylinders $(11,12)$ with calibrated spheres inserted in them with a small radial gap. The rotor nose is loaded by regulating the air pressure inside the cylinders. Two couples of capacitive displacement transducers measure the radial displacement of the rotor in correspondence of 
two measuring planes perpendicular to the spindle axis: one on the tool side (sensor item 9) and one on the motor side (sensor item 10). Another transducer (item 13 of figure 4 ) is used to measure the axial rotor displacement. The radial runout of the rotor in correspondence of the tool can be calculated on the base of these displacements with the hypothesis of rigid rotor.

The test bench depicted in figure $5 \mathrm{a}$ is used to test the electrospindle in dynamic conditions during machining. A reference system $x, y, z$ is fixed and centered in the center of the bushings with $x$ axis coaxial with the displacement transducer item 9. This bench differs from that of figure 4 (used for static measurements) because of the presence of the system shown in figure $5 \mathrm{~b}$, that replaces the load devices under the spindle.
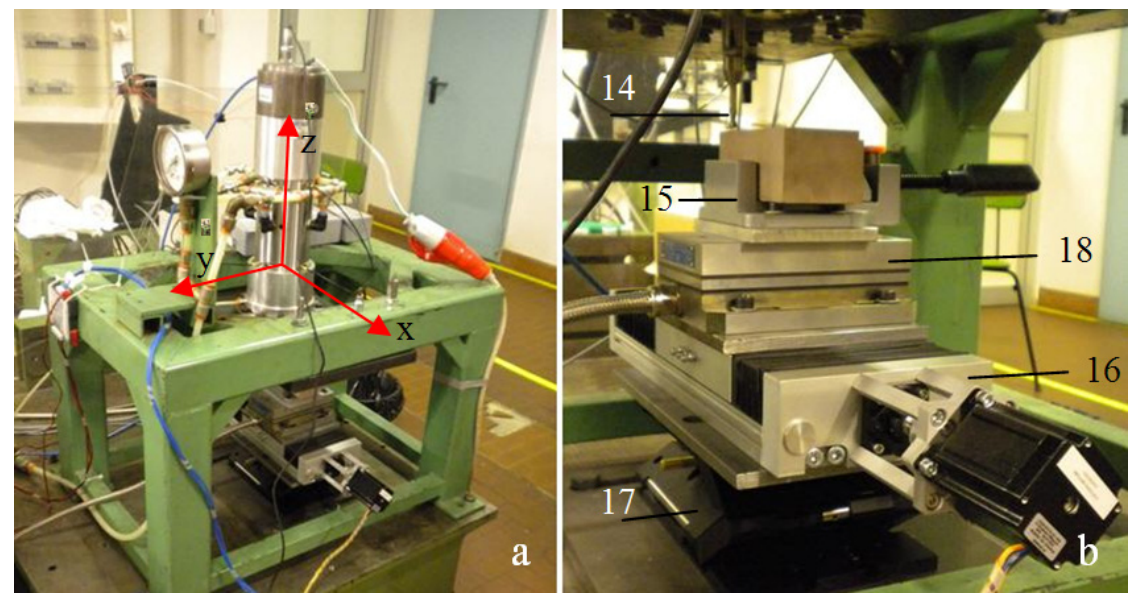

Figure 5: $\quad$ Test bench for the measurement of the cutting forces.

The system provides the advance along axis $x$ of the material under milling. High speed milling cutters (14) are mounted in a clamping tool. A block of rapid prototyping resin, fixed in the jaw (15), is advanced by the motorized slide (16). The motor used is a stepper motor with max. resolution 25600 steps/rev. The chip thickness can be regulated manually with the vertical slide (17). The cutting force is measured with the Kistler three-component force transducer (18), mounted between jaw (15) and slide (16). The dynamometer has $1 \mathrm{kN}$ full scale and $2 \mathrm{kHz}$ passband.

Tests were made up to $40000 \mathrm{rpm}$ with HSS tools of diameter 2.5, 4 and 6 $\mathrm{mm}$ and HSC tools of diameter 1,2 and $3 \mathrm{~mm}$.

\section{Experimental outcomes}

This section describes the test set-up for the experiments. Firstly the static stiffness of the bearings is determined at different supply pressures. Then the unbalance rotor response is shown, with also the FRF of the signal representing the spindle vibration. This demonstrates that the operation is stable. Deceleration 
tests were made to estimate the bearings frictional torque as a function of the rotational speed. The electrospindle was also tested during machining process and the effect of the cutting forces on the spindle vibration was detected.

\subsection{Static stiffness determination}

The electrospindle was mounted on a proper test bench with load devices. The test bench is described in [10]. These devices allow to load the spindle end radially also during low rotational speeds. Radial forces were imposed with different supply pressures and the radial displacement of the spindle end was calculated with linear interpolation of the displacements on the measuring planes. In figure 6 the radial load capacity vs. the spindle end displacement $r$ is depicted. The radial stiffness at $0.4 \mathrm{MPa}$ gauge supply pressure is about $24 \mathrm{~N} / \mu \mathrm{m}$

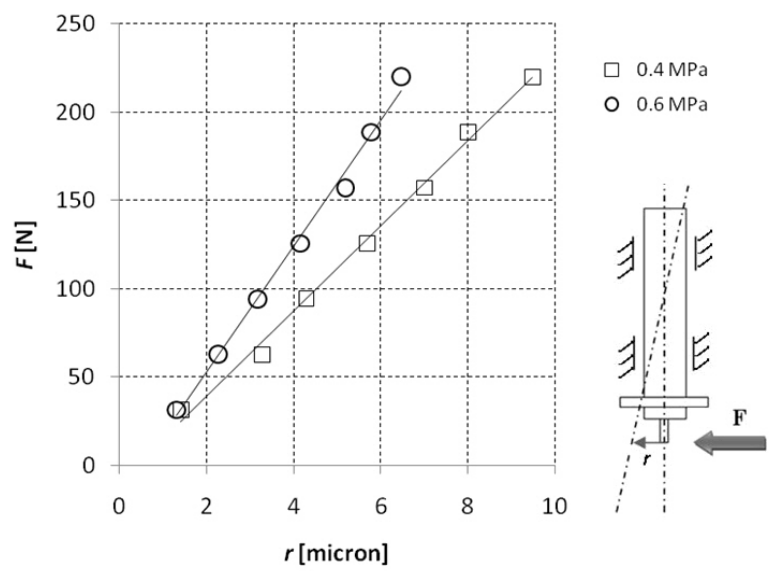

Figure 6: $\quad$ Radial force on the spindle end vs. displacement, $\omega=0$.

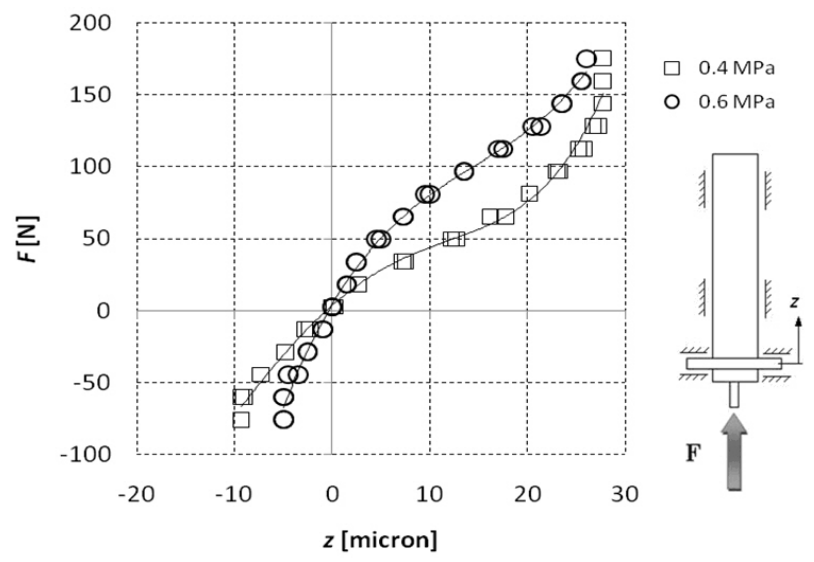

Figure 7: Axial load capacity at different supply pressures. 
and $35 \mathrm{~N} / \mu \mathrm{m}$ at $0.6 \mathrm{MPa}$. The axial load capacity vs. the axial displacement is represented in figure 7 . The axial stiffness at $0.4 \mathrm{MPa}$ is about $5 \mathrm{~N} / \mu \mathrm{m}$ and $12 \mathrm{~N} / \mu \mathrm{m}$ at $0.6 \mathrm{MPa}$. The air consumption of the bearings was measured with flow meters at different supply pressures (see figure 8).

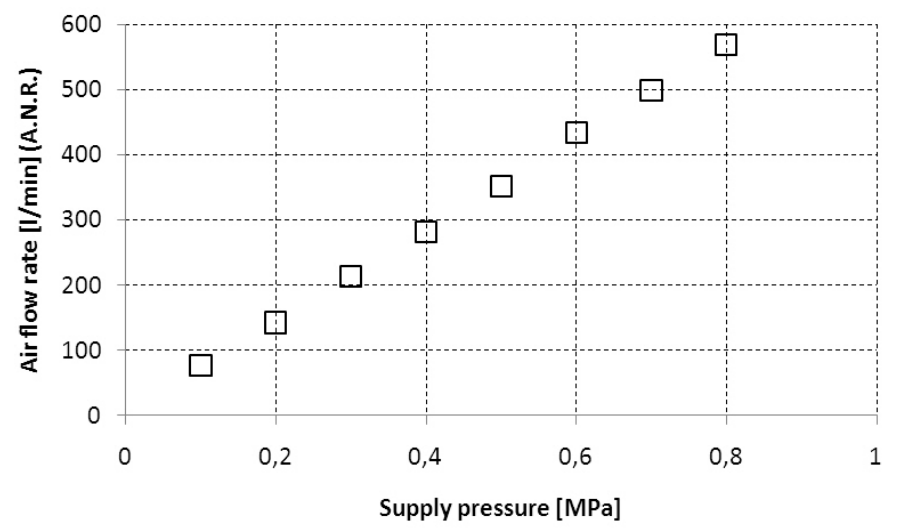

Figure 8: Air bearing consumption.

\subsection{Unbalance response}

The rotor orbits, measured in correspondence of the bushings on the tool and on the motor side, are shown in figure 9. They are relative to a $0.6 \mathrm{MPa}$ gauge supply pressure. These orbits appear not to be centered in the bushings because the relative rotor-sensor distance decreases due to the rotor centrifugal expansion. The spindle was tested up to $53000 \mathrm{rpm}$ and the tests were stopped because of the high rotor vibration. The permissible residual unbalance should be diminished in order to allow tests at higher speeds. Anyway, the whirl instability did not occur and the unbalance response was synchronous.
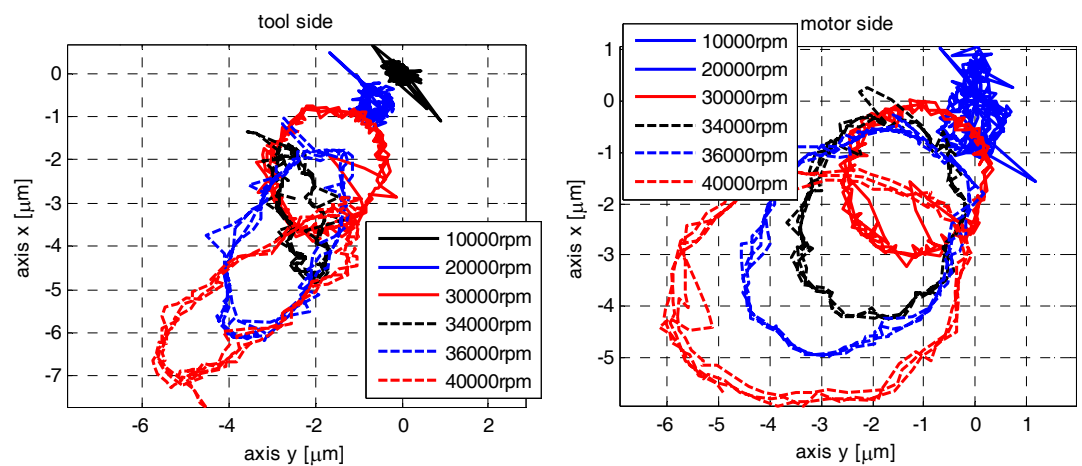

Figure 9: Rotor orbits in correspondence of a bushing due to the residual unbalance. 


\subsection{Analysis of bearing and windage losses}

The power dissipated in bearings and the windage losses were estimated by means of deceleration tests. In figure 10 the deceleration test from the initial speed of $38000 \mathrm{rpm}$ is visible as an example. From this test the friction torque was calculated knowing the rotating parts mass moment of inertia and measuring the deceleration. The friction torque is almost linear with the rotational speed, see figure 11.

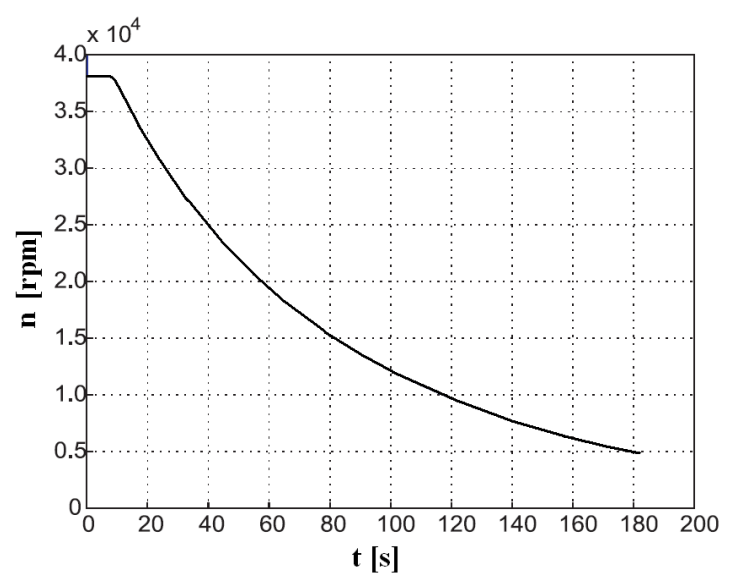

Figure 10: Deceleration test from $\omega=38000 \mathrm{rpm}$.

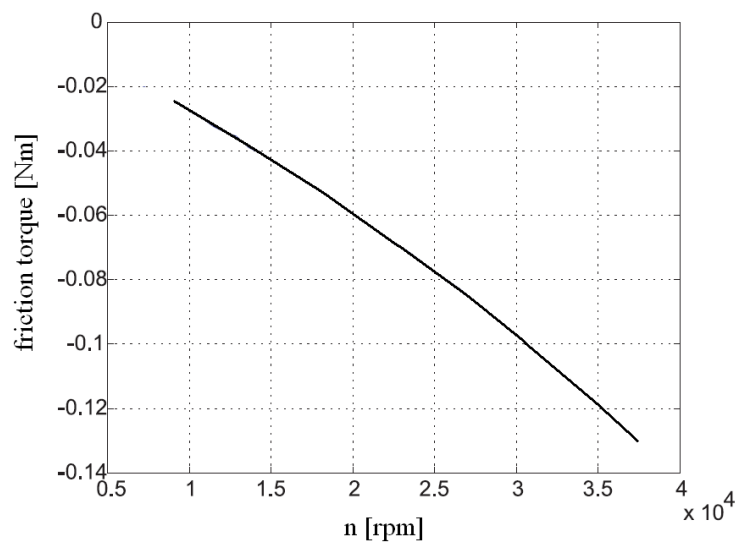

Figure 11: Friction torque vs. rotational speed.

\subsection{Effect of cutting forces}

Tests were made using high speed tools of different type and diameter. The tool represented in figure 12 is a $\mathrm{HSC}$ tool of diameter $3 \mathrm{~mm}$ and 2 sharp edges. 
Figure 13 shows the sketch of the system during machining. The reference system $x, y, z$ attached to the bearings axis, the tool sense of rotation and the material feed speed are visible. The displacement transducer (item 9 of figure 2) along $x$ axis is also visible in correspondence of the measuring plane. Figure 14 shows an example of cutting forces applied by the tool on the material measured concurrently with the rotor displacement. This displacement represented in the figure is measured along $x$ and $y$ axes on the measuring plane on the tool side. During these tests the material approaches the tool moving along $x$ axis in the negative direction. The three components of the cutting force are expressed with respect to the reference system $x, y, z$. The cutting force is low (about $30 \mathrm{~N}$ along $x$ and $y$ direction) so the spindle displacement respect to the centre of the displacement (about $1 \mu \mathrm{m}$ ) along $x$ axis in negative direction, due to the material feed speed in this direction. Furthermore the spindle displacement along $y$ axis is negative due to the tool sense of rotation.

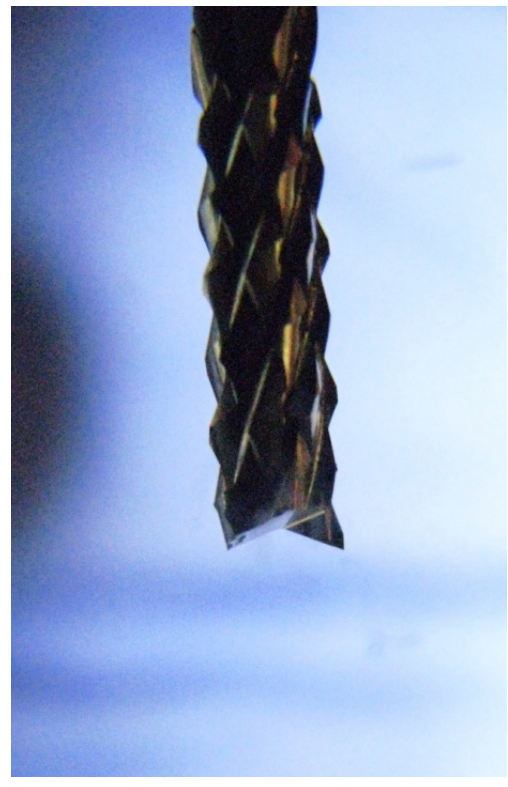

Figure 12: $\quad$ Photo of the HSC tool of diameter $3 \mathrm{~mm}$ and 2 sharp edges.

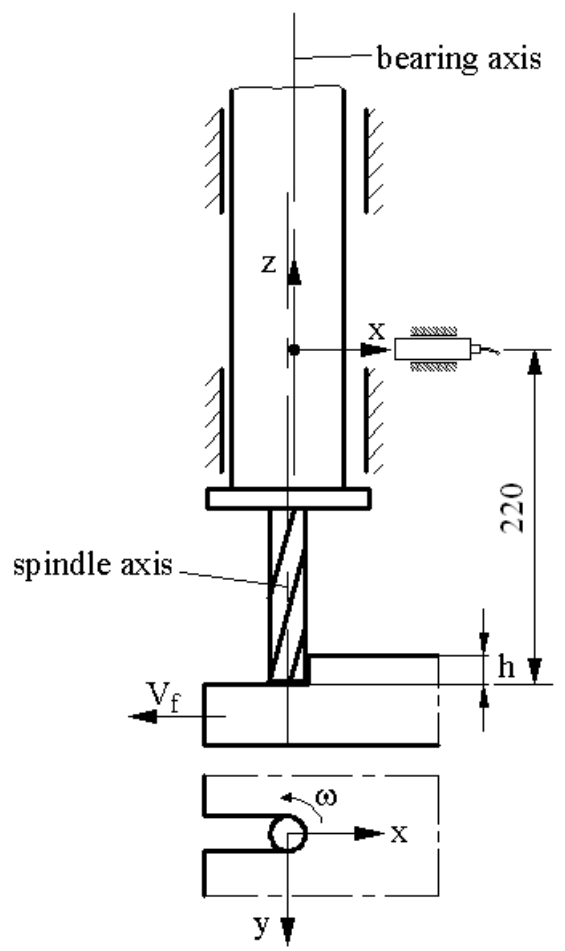

Figure 13: Sketch of the system during machining. 

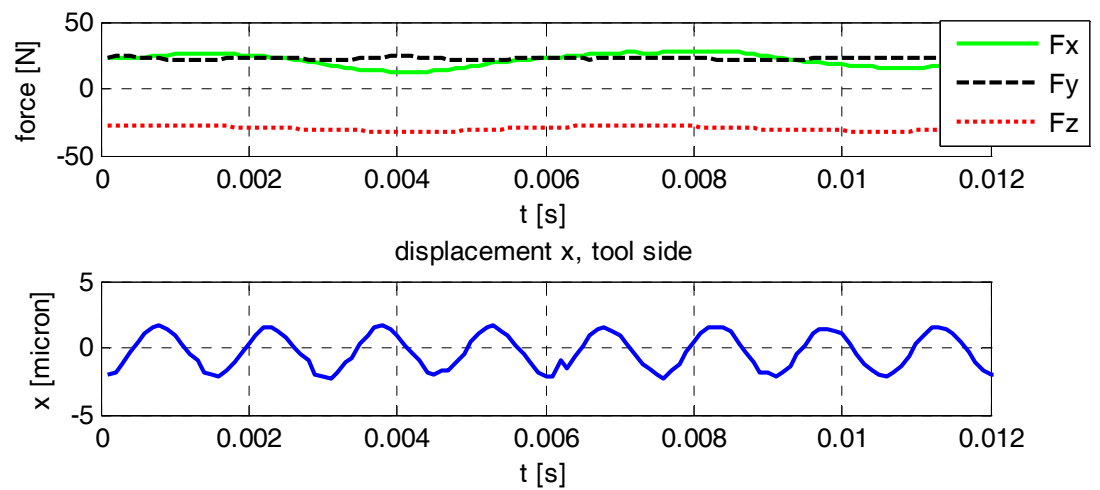

displacement $\mathrm{y}$, tool side

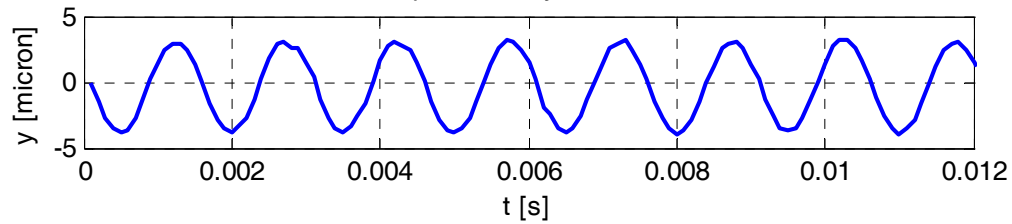

Figure 14: Cutting forces imposed by the tool on the material and rotor displacement along $x$ and $y$ axes; $\omega=40000 \mathrm{rpm}$, feed speed $a_{\mathrm{z}}=0.012 \mathrm{~mm} / \mathrm{sharp}$ edge; HSC tool of diameter $3 \mathrm{~mm}$; chip thickness $h=1 \mathrm{~mm}$.

In figure 15 the cutting force using the HSC tool of diameter $3 \mathrm{~mm}$ at different feed speeds $v_{\mathrm{f}}(1.5 \mathrm{~mm} / \mathrm{s}$ and $4.5 \mathrm{~mm} / \mathrm{s})$ is shown vs. the rotational speed. The chip thickness $h$ is $1 \mathrm{~mm}$. The force increases with the rotational speed and also with the feed speed $v_{\mathrm{f}}$.

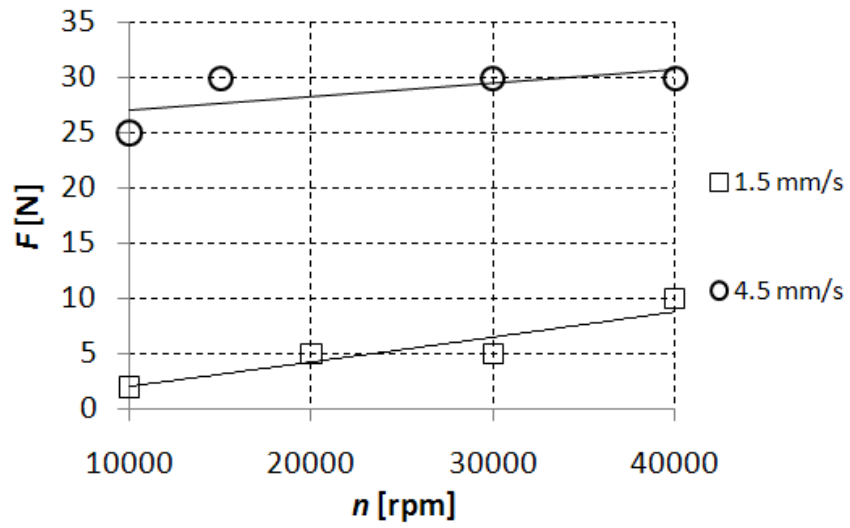

Figure 15: Cutting force vs. rotational speed; feed speed $v_{\mathrm{f}}=1.5$ and $4.5 \mathrm{~mm} / \mathrm{s}$, chip thickness $h=1 \mathrm{~mm}$. 


\section{Conclusions}

In this paper an electrospindle of nominal speed $75000 \mathrm{rpm}$, supported with gas bearings, is investigated. The bearing stiffness was improved respect to the prototype described in paper [9] because the diameter of the supply holes was changed. The electrospindle was tested also during machining using HSS and HSC tools of different diameter. A block of rapid prototyping resin was machined, with chip thickness $h=1 \mathrm{~mm}$ and different feed speeds.

The spindle was tested during machining up to $40000 \mathrm{rpm}$ with radial cutting forces lower than $50 \mathrm{~N}$ and it operated in stable conditions. This demonstrates the feasibility of the use of gas bearings for working spindles. Further tests are planned with higher cutting forces and operating speeds.

\section{References}

[1] Moore Precision Tools, Nanotechnology Systems, 2001.

[2] Ohishi S., Matsuzaki Y., Experimental investigation of air spindle unit thermal characteristics. Precision Engineering, 26, pp. 49-57, 2002.

[3] Precitech Precision, Nanoform ${ }^{\circledR} 350$ Technical Overview and Unsurpassed Part Cutting Results, 2001.

[4] Westwind, Available online: http://www.westwind-airbearings.com/ pcb/overview.html, 2008.

[5] Peirs et al. Micropower generation with microgasturbines: a challenge, $J$. Mech. Eng. Sci., 221, pp. 489-500, 2007.

[6] Zwyssig C. and Kolar J. W. Design considerations and experimental results of a $100 \mathrm{~W}, 500000 \mathrm{rpm}$ electrical generator, J. Micromech. Microeng., 16, S297-S302, 2006.

[7] Colombo, F., Raparelli, T., Viktorov, V. (2009). Externally pressurized gas bearings: a comparison between two supply holes configurations. Tribology International, Vol. 42, 303-310.

[8] Belforte, G., Raparelli, T., Viktorov, V. (1999). Theoretical investigation of fluid inertia effects and stability of self-acting gas journal bearings. ASME Journal of Tribology, Vol. 121, 836-843.

[9] Belforte G., Colombo F., Raparelli T., Trivella A., Viktorov V., High speed electrospindle running on air bearings: design and experimental verification, Meccanica, 43, pp. 591-600, 2008.

[10] Belforte G., Colombo F., Raparelli T., Viktorov V., Trivella A., An experimental study of high speed rotor supported by air bearings: test rig and first experimental results, Tribology International, 39, pp. 839-845, 2006. 
